\title{
Interannual variation of Gulf Stream heat transport in a high-resolution model forced by reanalysis data
}

\author{
N. M. J. Hall \& B. Barnier \& T. Penduff \& J. M. Molines
}

\begin{abstract}
The variability present in a 1/6th degree Atlantic ocean simulation forced by analysed wind stress and heat flux over a 20 -year period is investigated by means of heat transport diagnostics. A section is defined which follows the Gulf Stream and its seaward extension, and transport of heat across this section is analysed to reveal the physical mechanisms responsible for 'intergyre' heat exchanges on a variety of time scales. Heat transport across another section that crosses the Gulf Stream is also diagnosed to reveal the temporal behaviour of the 'gyre' circulation. The Ekman response to wind stress variations accounts for the annual cycle and much of the interannual variability in both measures. For the intergyre heat transports, cancellation by transientmean flow terms leads to a very weak annual cycle. Transient eddies account for approximately half the total intergyre transport of 0.7 Petawatts. They also account for a significant fraction of the interannual variability, but separate experiments with repeated-annual-cycle forcing indicate that the transient eddy component of the heat transport variability is internally generated. Links between the intergyre transport, the wind-driven gyre circulation, the surface heat budget and the atmospheric 'North Atlantic Oscillation' are discussed.
\end{abstract}

\section{Introduction}

The importance of the Atlantic Ocean for the global climate stems largely from its horizontal transfer of heat. Time variability in Atlantic Ocean heat transport mirrors time variability in other climatic indicators in the atmosphere and ocean. In the North Atlantic it is the Gulf Stream and associated gyre and eddy circulations that are responsible for the greater part of the heat

N. M. J. Hall $(\bowtie) \cdot$ B. Barnier · T. Penduff · J. M. Molines LEGI, BP53, 38041 Grenoble Cédex 9, France

E-mail: Nick.Hall@hmg.inpg.fr transport. Variability in Gulf Stream transports, both along and across the stream might therefore serve as a useful indicator of climate variability and of the way the atmosphere and ocean influence one another. For example, a mechanism involving interannual compensation between atmospheric and oceanic heat transports first postulated by Bjerknes (1964) has recently been taken up by Marshall et al. (2001) to describe a coupled system whose behaviour is determined by the response time of Gulf Stream heat transports to changes in atmospheric forcing. In fact the Gulf Stream responds to both wind stress and heat flux anomalies on a range of time scales from seasonal to interdecadal and a variety of processes are involved. These include Ekman currents and Rossby wave dynamics, nonlinear control of gyre circulations and transient eddy heat transports and large scale overturning circulations. It is therefore important to determine which processes contribute to heat transports on which time scales, and which processes are susceptible to atmospheric influence.

The large-scale atmospheric disturbances that give rise to anomalous ocean heat transports and sea surface temperature anomalies (SSTAs) have often been characterised by a single index, the North Atlantic Oscillation (NAO, see e.g. Hurrell 1996). In recent years there has been great interest in the coupling of the NAO with oceanic mechanisms that create and propagate temperature anomalies, and which maintain oceanic heat transports. Indeed, many of the recent modelling studies of North Atlantic variability have been couched in terms of the response to the NAO (Visbeck et al. 1998; Hakkinen 1999; Eden and Jung 2001; Pavia and Chassignet 2002; Gulev et al. 2003). The atmospheric NAO has power on all time scales but exhibits a slightly reddened spectrum, suggesting some long-term oceanic memory of the phenomenon. SSTAs generated by the NAO may therefore feed back on the atmospheric circulation. These SSTAs arise either from local forcing (seasonal to interannual time scales) or from anomalous advection (interannual to decadal time scales) and their 
propagation along the north Atlantic current can determine the nature and time scale of atmosphere ocean interaction (Hansen and Bezdek 1996; Sutton and Allen 1997; Saravanan and McWilliams 1997; Krahmann et al. 2001). Anomalies in large-scale current systems generated by the NAO manifest themselves as an anomaly gyre (Marshall et al. 2001) which straddles the Gulf Stream and can be interpreted as a change in the trajectory of the stream with an associated change in heat transport. Using a long time series of observed cross-stream temperature contrast, Czaja and Marshall (2001) present evidence that NAO-induced Gulf Stream heat transport anomalies do indeed feed back on the atmosphere on decadal time scales. The fact that atmospheric variability, and more specifically the NAO can also affect the trajectory of the Gulf Stream on interannual time scales has been confirmed observationally by Taylor and Stephens (1998) and Frankignoul et al.(2001). These studies give a response time of less than two years. Observations are, of course, unable to provide accurate information on interannual variations in heat transport, and for this we must turn to modelling studies.

Given the central role of horizontal ocean heat transports in recent discussions of Atlantic climate variability, it is timely to perform a detailed diagnosis in a realistic modelling framework, paying particular attention to the Gulf Stream. The model integrations considered should have the following properties:

1. Ekman heat fluxes should be adequately represented. The Ekman transport and the associated barotropic return flow can account for a large part of the annual cycle and interannual variability of the heat transport (Jayne and Marotzke 2001).

2. Gyre scale circulations, jet structures and magnitudes should be well simulated. The Gulf Stream should have a reasonable mass transport, velocity cross section and trajectory.

3. Mesoscale eddies should be adequately resolved, as they account for a significant fraction of intergyre transport, which is not necessarily well captured by diffusive parametrizations.

4. The model must be forced at the surface by some representation of atmospheric heat and momentum fluxes with realistic spatio-temporal characteristics, consistent with those of the NAO.

In this study we diagnose transports from the CLIPPER ocean model (Treguier et al. 2001), using an integration with $1 / 6$ degree horizontal resolution and 43 vertical levels, forced by European Centre for Medium range Weather Forecasts (ECMWF) analysis and reanalysis data for wind stress and surface heat flux from the years 1979-1999. We concentrate essentially on two sections across the Atlantic, shown in Fig. 1. One section follows the Gulf Stream and its seaward extension from Florida to Europe. The heat transport across this section represents fluxes from the subtropical gyre to the subpolar gyre. We will refer to it as the 'intergyre'

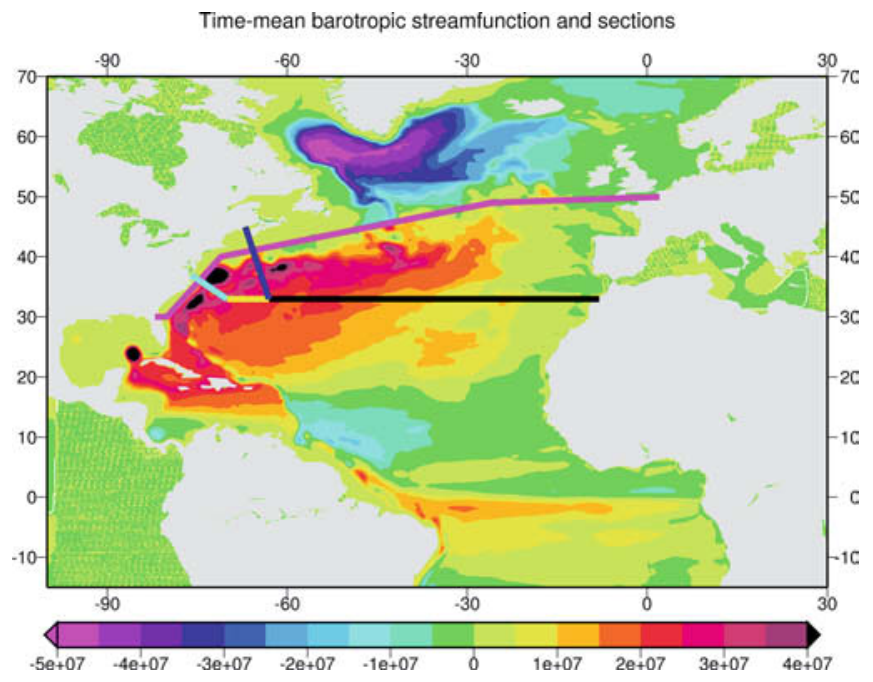

Fig. 1 Time mean barotropic stream function $\left(\mathrm{m}^{2} \mathrm{~s}^{-1}\right)$ for years 1980-1999 with sections used for calculation of heat transport superimposed. Magenta: Gulf Stream (intergyre transport), purple/ black cross-stream (gyre transport), blue/yellow/black, alternative cross-stream section

transport. The other section crosses the Gulf Stream at right angles and then follows the 33rd parallel to the North African coast. The transport across this section represents the heat flux within the Gulf Stream/subtropical gyre system. We will refer to it as the 'gyre' transport.

We analyse the time variability of 'intergyre' and 'gyre' transports in two integrations. One is forced with the daily reanalysis time series and the other is forced with the mean annual cycle of the weekly reanalysis time series. In this way we can attempt to gauge the effect of interannual variability in the forcing, and how important it is in generating interannual variability in the model transports. This work attempts to shed light on the following questions:

1. What oceanic processes are responsible for interannual variations in Gulf Stream heat transport?

2. How does Gulf Stream heat transport respond to interannual variations in surface conditions, for example the NAO?

3. To what extent is the magnitude and temporal behaviour of Gulf Stream heat transport contingent on atmospheric conditions?

In Sect. 2 further details of the model integrations and flux calculations are given and in Sect. 3 results are shown for the time series' of horizontal transports, with emphasis given to interannual variability of intergyre transports. The results are discussed in the context of the atmospheric forcing in Sect. 4. Conclusions are given in Sect. 5.

\section{Details of runs and calculations}

The time period considered in this analysis runs from February 1979 to the end of 1999. For this period the 
output for currents and temperature have been stored as consecutive 5-day means, a strategy that effectively eliminates aliasing from inertial motions, but still retains the essential information for transient fluxes (see Crosnier et al. 2001). Prior to the analysis period, the model was subjected to an 8-year spinup, using the weekly mean climatology from the atmospheric reanalysis, so that only the details of the annual cycle were retained in the surface forcing, and not the interannual variability. In one integration this mean-annual-cycle forcing was simply continued for another 20 years. We call this the 'annual cycle' run. In the other integration the actual daily reanalyses (1979-93) and analyses (1994-99) were used to provide an experiment with forced interannual variability. We call this the 'interannual' run. In both cases, constant hydrographic data were used to provide mass fluxes and temperature profiles at the open boundaries of the model (the Drake passage, the Aghulas passage, the straits of Gibraltar and the Arctic Ocean) using the method described by Treguier et al. (2001).

The motivation for diagnosing two runs with with different forcing is to examine the effect on the interannual variability. The annual cycle run has no interannual variability in the forcing. Any interannual variability seen in the model heat transport in this run is therefore generated by internal dynamics. In the diagnosis that follows we will attempt to identify different dynamical mechanisms for internally and externally generated model variability by comparing the two runs. Another feature of the annual cycle run is that the forcing contains no short (sub-weekly) time scale 'weather noise'. This is a normal consequence of taking a mean annual cycle over a sufficient number of years. Weather noise forcing is a deviation from the annual cycle and as such, can be interpreted as another form of interannual variability. If short time scales exist in the 20 -year mean annual cycle they are unlikely to have any physical significance. In our case we guarrantee their removal by using weekly mean values for surface heat flux and wind stress. It is feasible that this could influence the directly forced component of transient oceanic heat transport, but it will be seen that this is unlikely to affect its interannual variability. This is because the currents respond rapidly but the temperatures take longer to adjust. Integration of the flux up to the weekly time scale is therefore linear, and still accounted for with smoothed annual cycle forcing.

While the reanalysis wind stress is applied directly to the model, the surface heat flux is subjected to a correction and is specified as follows:

$Q_{\mathrm{tot}}=Q_{s r}(z)+Q_{l r}+Q_{l+s}+\frac{\partial Q}{\partial T}(x, y$, season $)\left(T_{c}-T\right)$,

where the terms on the right are respectively: shortwave radiation (penetrative); longwave radiation and latent plus sensible heat flux (all provided by reanalysis data) and finally a correction term in which $T$ is the model's surface temperature and $T_{c}$ an observed (Reynolds and
Smith 1994) weekly climatology. Details of this forcing strategy, including the determination of $\frac{\partial Q}{\partial T}$, are given by Barnier (1998). The presence of the correction term is essential to guarantee that the model has a reasonably realistic climatology, and it also serves to allow the model some degree of liberty in its horizontal heat transport, which would otherwise be determined entirely by external flux data (barring seasonal storage terms). If this term were to be left out, there would be an implicit assumption that the ocean model is perfect, and that it is in perfect synchronisation with the observed atmosphere, so the two systems are interacting exactly as in the observations. In fact the model and flux estimates contain errors, and cannot be expected to give a perfect match to the observed time development of the fluxes. To be physically consistent we must therefore accept that its horizontal fluxes and its interaction with the atmosphere would be different. The correction term thus represents an approach to a more physically consistent, if less realistic, coupled system, and can be viewed as part of the representation of the ocean's interaction with the free atmosphere in the absence of full coupling. It does, however, add a term to the surface interaction that is not present in the observations, and which is sometimes quite large. Salinity is treated in a similar way to temperature with a pseudo-salt flux derived from analysed evaporation minus precipitation and climatological river runoffs. Likewise, a correction term is applied with the same coefficient as for heat flux. For further details see Treguier et al. (2001).

Figure 1 shows a long-term mean (1980-1999) of the barotropic (depth integrated) stream-function from the interannual run. Note that the tight gradients that represent the Gulf Stream separate from the coast somewhat north of Cape Hateras, a ubiquitous error for $z$-coordinate primitive equation models. There is a permanent standing recirculation feature at the point of separation, which is more compact and further north than the observed recirculation gyre. The mass transport and cross-stream velocity profile of the stream are, however, quite realistic owing to the model's relatively high resolution. Superimposed on Fig. 1 are the sections defined for the calculation of transports. The 'Gulf Stream' section has been chosen to loosely follow a contour of barotropic stream-function and is completed to connect with the European coast. 'Intergyre' transport is calculated across this section. The 'cross stream' section cuts across the Gulf Stream at right angles and then follows the $33^{\circ} \mathrm{N}$ latitude circle. The 'gyre' transport is calculated across this section. A second option is also defined that cuts across the Gulf Stream before it separates from the coast.

The heat transports across these sections are given by

$[v T]=c_{p} \rho \int_{-H}^{0} \int_{W}^{E} T(-\hat{\mathbf{k}}) \cdot \mathbf{v} \times \mathbf{d s} d z$.

The section starts at the western boundary and ds is a distance element along the section. Heat transport due 
to velocity vector $\mathbf{v}$ and temperature $T$ is positive to the left ( $k$ is the vertical unit vector), i.e. from the southern into the northern part of the basin. Model variables are defined on an Arakawa $\mathrm{C}$ grid and the calculation was carried out across segments that run along a staircase between stream function/vorticity points. Appropriate northward or eastward velocities are defined at the mid points of these segments. Temperatures were interpolated horizontally onto the velocity points from the two grid boxes either side of the segment. There is a good deal of cancellation in this calculation and double precision was necessary to ensure that the expected mass transport was obtained, and that the heat transport was stable to small redefinitions of the boundary.

All sections that join the two coasts have a constant net mass transport to the south of $10^{9} \mathrm{~kg} \mathrm{~s}^{-1}$ or $1 \mathrm{~Sv}$. This is the mass transport that enters at the northern boundary and leaves at the eastern boundary in addition to the Antarctic circumpolar transport. Its existence leads to conceptual problems in calculating the heat transport, which depends on the scale chosen for temperature. If the temperature is measured in Kelvins, the heat transport is everywhere southwards owing to the mass transport. This heat transport is real, but irrelevant since heat lost to the south is immediately replaced from the north and so there is no impact on surface fluxes and no importance for climate variability. Formally, the heat transport input at the north should be subtracted. By observational convention, we just use Celsius instead of Kelvin, implicitly assuming that the water at the northern boundary has a uniform temperature of zero Celsius. The associated constant error is insignificant compared to typical cross-latitude heat transports.

In the next section we present time series of heat transports calculated in this way. In cases where the annual cycle has been removed, the following procedure was applied. A mean value for each day of the year was calculated. This was done by taking the stored 5-day mean values from the model and assigning to them their mid-point date. An average for each date was then taken over all realisations in the 20 -year run for each date. For dates with no realisations a value was assigned by linear interpolation. The resulting mean annual cycle was then smoothed with a 21-day running mean and finally subtracted from the 20-year time series, again assigning appropriate mid-point dates to the 5-day mean values that make up the time series

\section{Heat transports}

The northward transport of heat in the Atlantic is a strong function of latitude, and this is borne out by the model integration. The annual mean transport peaks at $15^{\circ} \mathrm{N}$, and shows a steep decline between 30 and $50^{\circ} \mathrm{N}$. Figure 2 shows the annual mean transport for a number of individual years from the integration, illustrating the degree of interannual variability. The amount of variability, and the strength of the annual cycle (not shown)

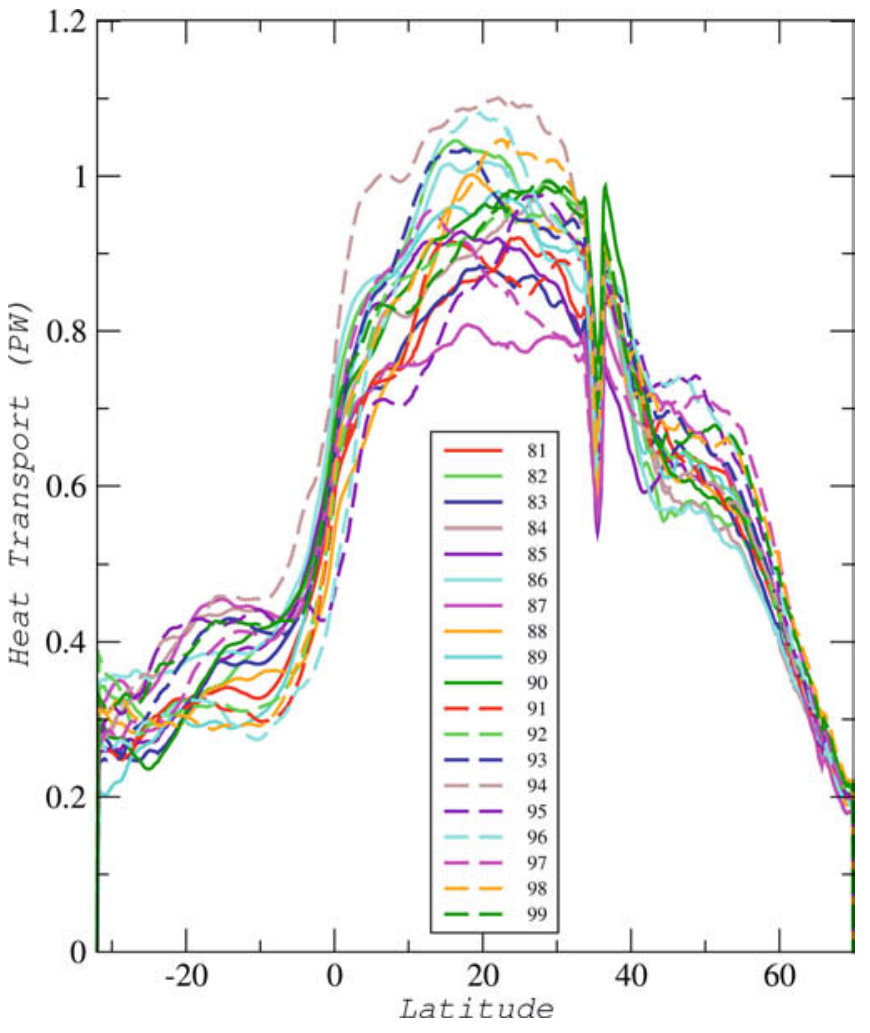

Fig. 2 Annual mean cross-latitude heat transport as a function of latitude for each year from 1982 to 1993 . The discontinuity at $36^{\circ} \mathrm{N}$ coincides with the open boundary in the Gulf of Cadiz

are similarly functions of latitude. The greater the transport, the more variable it is and this variablility and seasonality also declines rapidly north of $30^{\circ} \mathrm{N}$. The model heat transport is within the range of observed estimates shown in Ganachaud and Wunch (2003, see their Fig. 3). Although it is low in the tropics and Southern Hemisphere compared with their own estimate the agreement in the Gulf stream region is good.

These basic facts about cross-latitude transport provide the backdrop for interpreting time series' of intergyre heat transport across the Gulf Stream section, and gyre heat transport across the cross-stream section. These time series are displayed in Fig. 3. It can be seen immediately that the intergyre and gyre transports, as defined here, have a very different character to their time-variability. The gyre transports have a strong annual cycle while the intergyre transports have almost none. The peak to peak magnitudes of their respective (smoothed) annual cycles are $0.484 \mathrm{PW}$ (gyre) (one PW $=10^{15}$ Watts) and $0.193 \mathrm{PW}$ (intergyre) (the respective standard deviations are $0.147 \mathrm{PW}$ and $0.041 \mathrm{PW}$ ). Part of this difference is due to the difference in mean latitude of the two sections: the annual cycle is stronger at $33^{\circ} \mathrm{N}$, where the cross-stream section connects with the eastern boundary, than it is at $50^{\circ} \mathrm{N}$ where the Gulf Stream section connects. In fact the annual cycle for the intergyre transport has a magnitude equivalent to transport across $45^{\circ} \mathrm{N}$, while the annual cycle for the gyre transport is actually stronger than the transport at $33^{\circ} \mathrm{N}$. 
However, the level of interannual variability for gyre and intergyre transports is comparable. After removing the annual cycle, as shown in the red curves in Fig. 3, the smoothed intergyre transport has a standard deviation of $0.060 \mathrm{PW}$ over the 20-year period, and the gyre transport $0.084 \mathrm{PW}$. The corresponding values for straight latitude sections at $45^{\circ} \mathrm{N}$ and $33^{\circ} \mathrm{N}$ are $0.065 \mathrm{PW}$ and $0.109 \mathrm{PW}$, a more marked contrast. Furthermore, it could be argued that some of the interannual variability shown in the red curve in Fig. 3b is, in fact, a modulation of the large annual cycle seen in the gyre transport, and that the variability of annual mean transports across the two sections is still closer. We therefore suggest that the choice of sections, one following the mean flow and the other crossing it, has served to highlight different aspects of the variability.

For the rest of this section we will try to break down the time series' shown in Fig. 3 into physically meaningful composites to illustrate the processes at work. We start with the meridional overturning circulation (MOC). A large part of the mean transport of heat can be explained in terms of warm thermocline water flowing north and a cold deep return flow. The section mean of the MOC and its time development is depicted in Fig. 4 $\mathrm{a}, \mathrm{b}$ in terms of the mass transport in three layers, which correspond approximately to the mixed layer (red), the main thermocline (blue) and the deep (purple) water. Recall that the sum of these three components is a

\section{(a) Intergyre Transport}

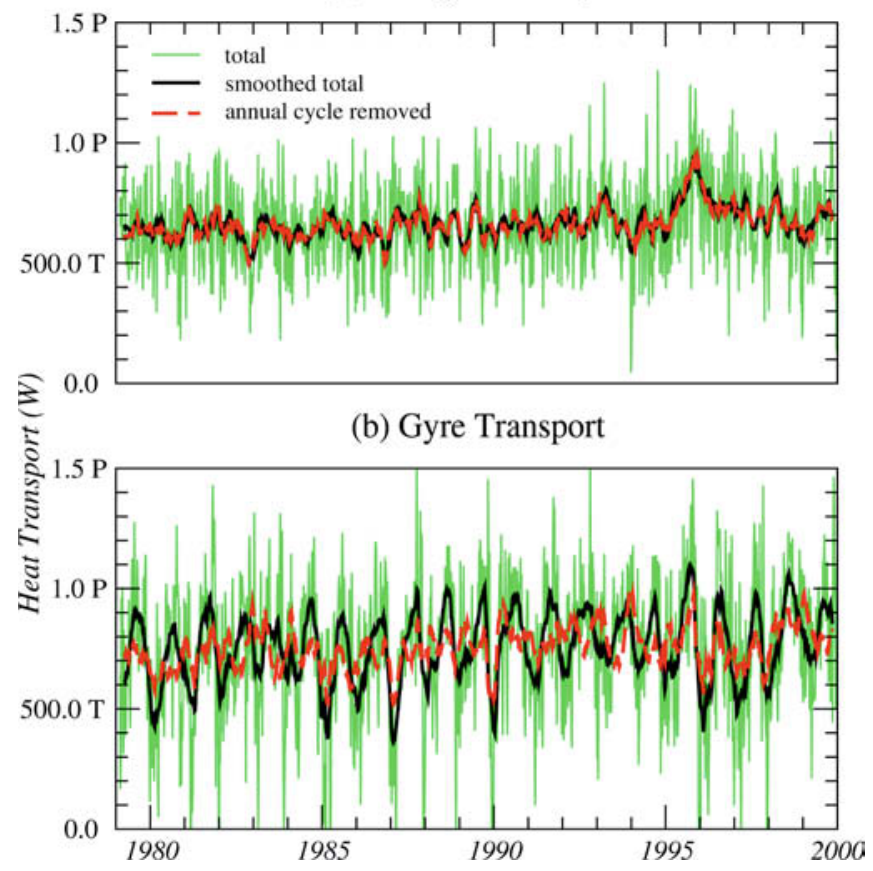

Fig. 3 Time series of total heat transport in Watts across the two main sections shown in Fig. 1: a intergyre transports (Gulf Stream section) and $\mathbf{b}$ gyre transports (cross-stream section). Green curves show the total and black and red curves have been filtered with a 21-point (105-day) running mean. The red curves have also had the annual cycle removed. All absiscae are in engineering notation, $P$-Peta $\left(10^{15}\right), T$-Tera $\left(10^{12}\right), G$-Giga $\left(10^{9}\right)$ constant $1 \mathrm{~Sv}$ to the south for both sections. The two sections have similar vertical decompositions for the time mean. In both cases there is an obvious cancellation between shallow and deep flow for the annual cycle. This observation is consistent with the notion that a large part of the annual cycle can be attributed to Ekman fluxes at the surface and a barotropic return flow (Jayne and Marotzke 2001). In terms of heat transport, this situation translates into a large signal in the mixed layer with a very weak compensating signal in the cold deep water. For the intergyre heat transports (Fig. 4c) the annual cycle is noticeably weaker than for the mass flux, indicating some cancellation from the annual cycle of temperature. There is also a large degree of cancellation between the mixed layer and the thermocline. For the gyre transports (Fig. 4d) there is a very strong annual cycle in the mixed layer and it is reinforced in the thermocline. The annual cycle has been removed in Figs. 4e, $\mathrm{f}$ to show the interannual variability in heat transport for the three layers. In terms of mass transport (not shown) there is still strong cancellation between shallow and deep water, but the variability in the heat transport is again carried by the warmer shallow water. This prompts the question: "to what extent do the processes responsible for annual and interannual variability differ?'.

The variability in heat transports is not just controlled by the MOC. It can also be viewed as a residual

$\begin{array}{lll}\text { (a) Intergyre } & \text { Mass } & \text { (b) Gyre }\end{array}$
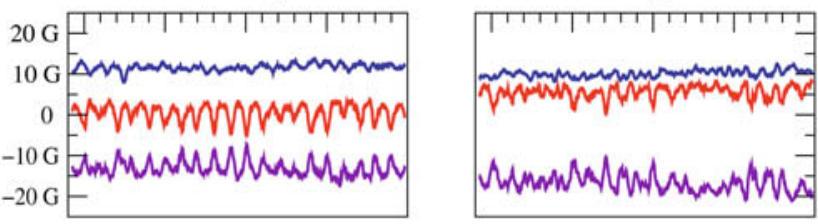

(c) Heat

(d)

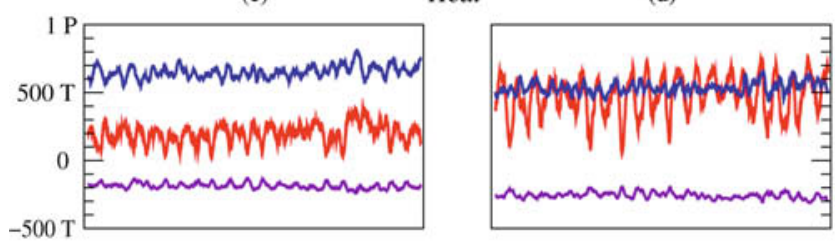

(e) Heat: annual cycle removed (f)

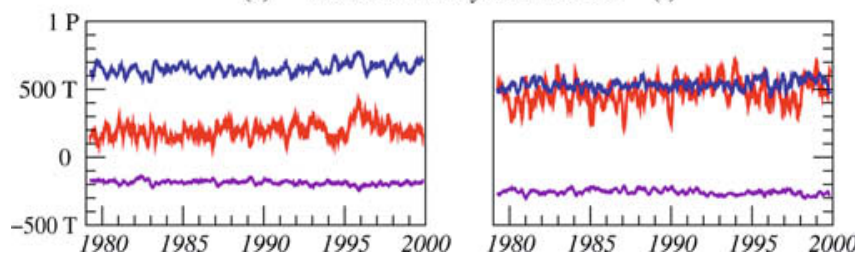

Fig. 4 Time series of mass and heat transports (positive towards the northern side) for three different levels: 0-200 m (red); 200$1000 \mathrm{~m}$ (blue) and $1000 \mathrm{~m}$-bottom (purple). a,b mass transport in $\mathrm{Kg} \mathrm{s}^{-1}\left(1 \mathrm{G} \mathrm{Kg} \mathrm{s}^{-1}=1\right.$ Sverdrup); c,d heat transport in Watts and d,e heat transport with annual cycle removed. a,c,e Intergyre transports; b,d,f gyre transports. All curves are filtered with a 105day running mean 
of horizontal northward and southward heat transports within and between gyres. We expect any cancellation effect to be more acute for gyre transports, because the mean flow crosses the section both ways. Figure. 5 displays the large degree of cancellation that exists for gyre transports for two cross-stream sections. The first (Fig. 5a) shows separate timeseries' for heat transports across the part of the cross-stream section that is perpendicular to the stream (purple), and the part that follows a line of latitude to the eastern boundary. The heat transport of the separated Gulf Stream is returned in large measure by the basin scale gyre. The second (Fig. 5b) shows time series' for a section that crosses the Gulf Stream before it separates, and for the short latitude section that then connects this to the bend in the previous cross-stream section. Barring heat storage in the Gulf Stream recirculation region, the sum of these two section transports should equal the transport across the (purple) perpendicular element shown in Fig. 5a. Again we see strong cancellation, between the unseparated Gulf Stream and the local recirculation. In both cases there is cancellation for all time scales as well as for the mean flow, and it is closely linked to the conservation of mass for currents that cross the section elements. Comparing the two panels in Fig. 5a with one another and with Fig. $3 b$ it is clear that we should not expect variations in the strength of the Gulf Stream to translate in a simple way into variations in gyre (or intergyre)

(a) Separated Stream / Basic Scale Gyre

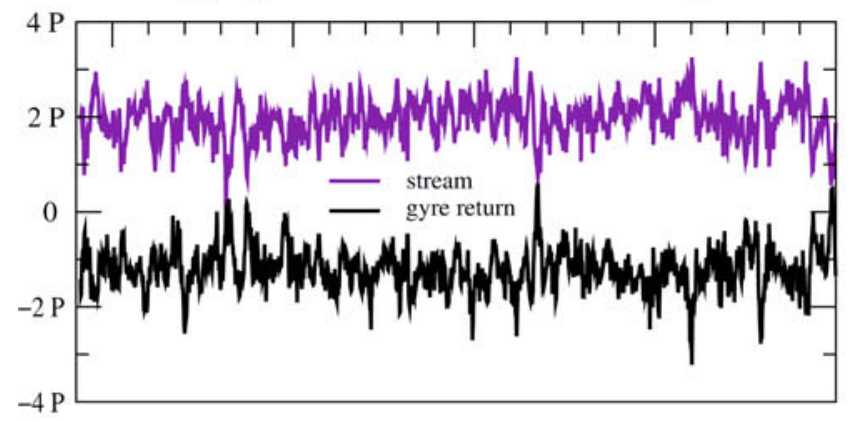

(b) Unseparated Stream / Recirculation

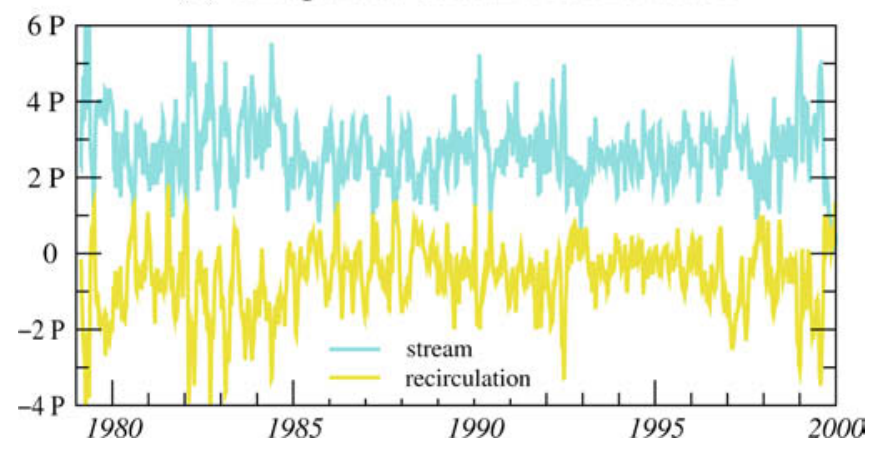

Fig. 5 Heat transports across section elements. The colours of the curves match the colours of the section elements shown in Fig. 1. a Cancellation between separated Gulf Stream flux and basin scale return flux. b Cancellation between unseparated Gulf Stream flux and local recirculation transports. Lead-lag correlations between the separated Gulf Stream transport (Fig. 5a, purple) and the gyre transport (Fig. 3b) give no indication of any significant relationship between these two measures. Once the annual cycle has been removed, the simultaneous correlation between the smoothed time series' for separated and unseparated Gulf Stream transports shown in Fig. 5 a,b (purple and blue) is also very close to zero, and actually decreases to -0.2 when the unseparated section leads by about 150 days. This behaviour raises questions about the role of nonlinearity in the local recirculation. The standing eddy seen in Fig. 1 is located between the two perpendicular cross-stream sections, and it is likely that it acts as a generator of internal variability.

We now turn our attention to intergyre fluxes and the variability of integrated heat transport across the Gulf Stream section. The fact that the section is roughly aligned with the time-mean barotropic flow means that the depth integrated mean flow plays a relatively small part in transporting properties across it. Mean intergyre transports are effected by baroclinic overturning circulations and by coherent mesoscale eddies. These components of the transport also contribute to the timevariability, as does the transient meandering of the stream. In fact the time series of intergyre transport can be broken down into eight components according to the following relation:

$$
\begin{aligned}
{[v T]=} & {[\bar{v}][\bar{T}]+\left[\bar{v}^{*} \bar{T}^{*}\right]+\left[v^{\prime}\right][\bar{T}]+[\bar{v}]\left[T^{\prime}\right]+\left[v^{*} \bar{T}^{*}\right]+\left[\bar{v}^{*} T^{\prime *}\right] } \\
& +\left[v^{\prime}\right]\left[T^{\prime}\right]+\left[v^{*} T^{\prime *}\right]
\end{aligned}
$$

where square brackets [] denote the average of a quantity along the section and stars * denote deviations from the section mean (weighted by segment length). Overbars represent average in time over the twenty years and prime denotes deviations from this time average. Each term in the expression is integrated in the vertical to produce the final diagnostic. Only the first two terms and the last two terms contribute to the time-mean transport (the first two terms being constant in time) since terms that are first order in primed quantities dissapear in the time mean. They do, however, contribute importantly to the variability, and to see how, we must try to characterise the physical processes associated with each term.

1. $[\bar{v}][\bar{T}]$ Section mean: this is the time-mean heat transport due to the section-average time-mean cross-section flow transporting the section-average time-mean temperature. It is time independent and largely reflects the mean effect of the overturning circulation.

2. $\left[\bar{v}^{*} \bar{T}^{*}\right]$ Mean stationary wave: this is the time-mean transport due to the spatial covariance of time-mean normal velocity and temperature along the section. It is also time independent, and measures in-phase variations of the overturning circulation and the vertical temperature structure along the section.

3. $\left[v^{\prime}\right][\bar{T}]$ Baroclinic cycling: this is the time variability due to flucutations in the section-mean normal 
velocity and their vertical covariance with sectionmean time-mean temperature. Non-zero values imply a vertical covariance because the mass transport across the section is time independent.

4. $[\bar{v}]\left[T^{\prime}\right]$ Temperature cycling: this is the time variability due to fluctuations in section-mean temperature.

5. $\left[v^{*} \bar{T}^{*}\right]$ Stream meander: this is the time variability due to along-section spatial covariance between normal velocity fluctuations and mean temperature. It can be interpreted as a measure of variability in the orientation of the Gulf Stream jet on all scales.

6. $\left[\bar{v}^{*} T^{\prime *}\right]$ Isotherm meander: this is the time variability due to the along-section spatial covariance between temperature fluctuations and mean normal velocity. It can be interpreted as a measure of variability in the orientation of the Gulf Stream front on all scales.

7. $\left[v^{\prime}\right]\left[T^{\prime}\right]$ Transient MOC: this is the transport and variability due to the time covariance of fluctuations in section-mean normal velocity and temperature. It has a non-zero time mean, and as with the baroclinic cycling term, it requires vertical covariance between velocity and temperature because the mass transport is constant.

8. $\left[v^{*} T^{\prime *}\right]$ Transient eddies: this is the transport and variability due to time-space covarying anomalies. It is generated by coherent structures in time and space. We identify this term with the action of mesoscale eddies.

Figure. 6 shows time series' of these terms for the intergyre transports (across the Gulf Stream section). The mesoscale eddies $\left[v^{* *} T^{* *}\right.$ (red curve) account for between one third and one half of the total mean transport, and the eddy transport is also highly variable on interannual time scales, although it appears to have no annual cycle. The 'stream meander' $\left[v^{\prime *} \bar{T}^{*}\right]$ (magenta) and 'isotherm meander' $\left[\bar{v}^{*} T^{\prime *}\right]$ (orange) terms do not contribute to the mean transport, but they are clearly also very important for the interannual variability. Unsurprisingly, there is some degree of cancellation between the two, as fluctuations in the path of the Gulf Stream jet accompany fluctuations in the position of the Gulf Stream front. The sum of the two meander terms also cancels to some extent the variability in the eddy transport. This suggests an almost simultaneous link between fluctuations in the path of the Gulf Stream and the generation, and transport of heat by the eddy field. The mean flow terms are relatively small, owing to our choice of a flow contour for the section. The 'cycling' terms have a strong annual cycle although the 'baroclinic cycling' term $\left[v^{\prime}\right][\bar{T}]$ (purple) also contains much high frequency noise. Note that the two cycling terms are in opposition, weakening the annual cycle. Interestingly, the remaining annual cycle is eliminated by the meander terms. There is thus a cancellation between the transient overturning behaviour of the intergyre transport and the annual cycle of horizontal covariance in the eddy field. If the meander terms are mainly contributed by baroclinic eddies, this is dynamically consistent with (a) Total, eddy and meander terms

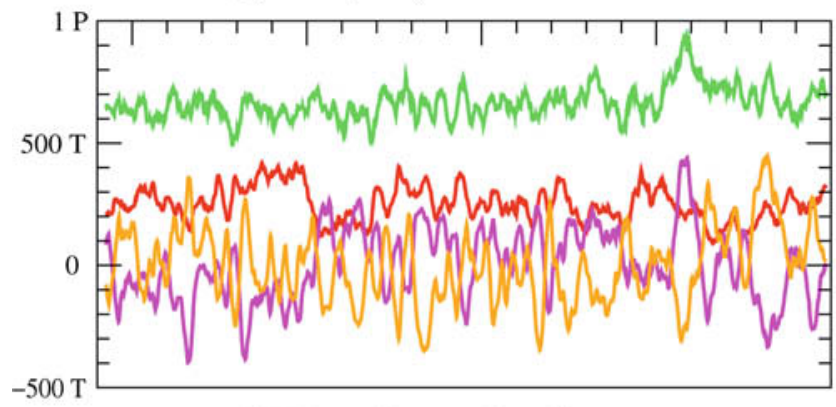

(b) Mean flow and cycling terms

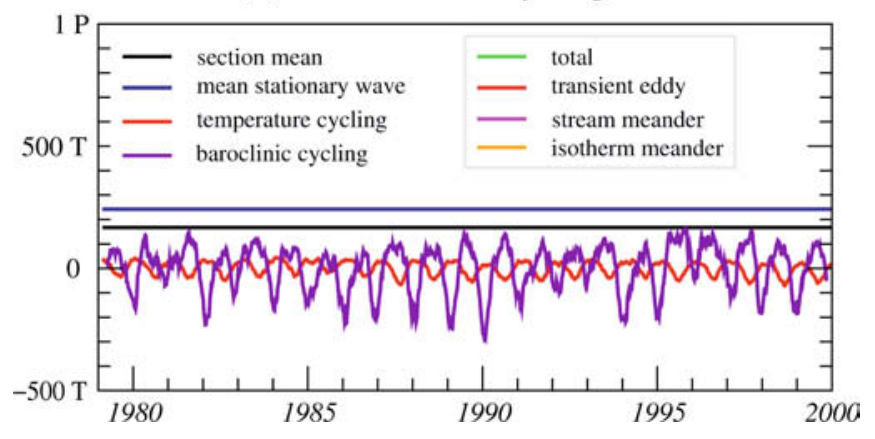

Fig. 6 Components of intergyre heat transport, see text for details a total (green), stream meander $\left[v^{\prime *} \bar{T}^{*}\right]$ (magenta), isotherm meander $\left[\bar{v}^{*} T^{*}\right]$ (orange) and transient eddies $\left[v^{*} T^{\prime *}\right]($ red $)$. b Section mean $[\bar{v}][\bar{T}]$ (black), mean stationary wave $\left[\bar{v}^{*} \bar{T}^{*}\right]$ (blue) baroclinic cycling $\left[v^{\prime}\right][\bar{T}]$ (purple) and temperature cycling $[\bar{v}]\left[T^{\prime}\right]$ (red). All curves are filtered with a 105-day running mean

the cancellation noted in the annual cycle between the thermocline and the mixed layer seen in Fig. 4c. The 'transient MOC' term $\left[v^{\prime}\right]\left[T^{\prime}\right]$ (not shown) is negligibly small.

The same analysis can be done for the gyre transport, and this is shown in Fig. 7. The mean flow component is now very large and the contribution of eddies relatively small. Variability due to eddies and 'meanders' is also reduced. The large annual cycle, and much of the interannual signal comes from the baroclinic cycling term $\left[v^{\prime}\right][\bar{T}]$ (purple), which represents baroclinic pulses in gyre strength. Note that the temperature cycling term $[\bar{v}]\left[T^{\prime}\right]$ now reinforces this annual cycle.

Now that the annual cycle and interannual variability in gyre and intergyre heat transport has been broken down into components that represent recognisable physical phenomena, we are in a better position to assess the direct influence of the atmosphere, and return to the question of how the mechanisms responsible for interannual variability differ from those responsible for the annual cycle. The most direct expression of the atmospheric influence is the Ekman transport. The similarity between variations in mass and heat transports across section elements suggests that the Ekman transport plays an important role. It can be easily calculated from the imposed wind stress along the section according to

$[v T]_{e k}=-\frac{c_{p}}{\rho} \int_{W}^{E}\left(\frac{T_{e k}}{f}\right) \vec{\tau}_{s} \cdot \mathbf{d s}$, 
(a) Total, eddy and meander terms

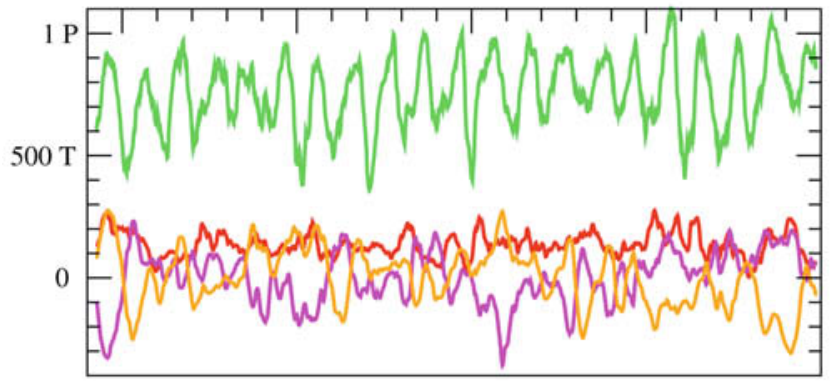

(b) Mean flow and cycling terms

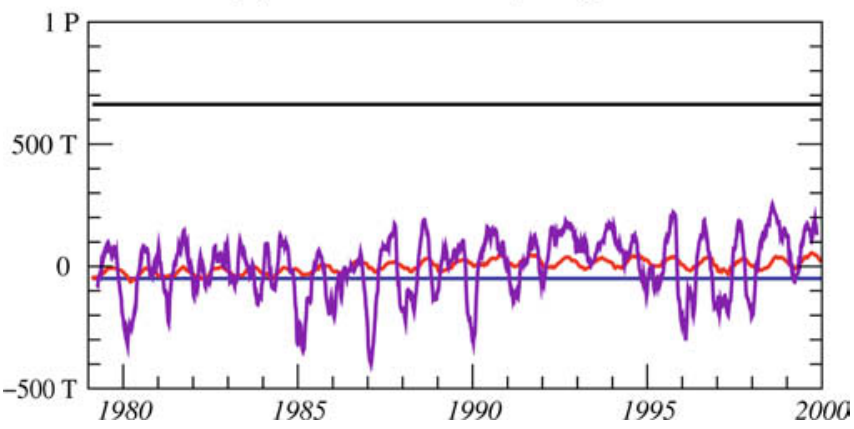

Fig. 7 As Fig. 6 but for gyre transports

where $T_{e k}$ is the depth averaged temperature within the Ekman layer and $\vec{\tau}_{s}$ is the surface wind stress. The calculation is not very sensitive to the depth chosen for the Ekman layer: we used a value of $150 \mathrm{~m}$. The Ekman heat transport calculated in this way can be broken down into components as before. The results are shown in Fig. 8. Practially all the variability due to Ekman transports is contained in the baroclinic cycling term $\left[v^{\prime}\right][\bar{T}]$. There is also a smooth annual cycle in the temperature cycling $[\bar{v}]\left[T^{\prime}\right]$. These two terms match their total intergyre values very closely. They effectively isolate the Ekman contribution. The Ekman component of transient eddy $\left[v^{*} T^{* *}\right]$ and stream meander $\left[v^{\prime *} \bar{T}^{*}\right]$ terms is negligible. The question that remains is how much of the interannual signal is generated by Ekman transports. To answer this, the annual cycle was removed from the baroclinic cycling term for the total intergyre transport and for the Ekman contribution. They are plotted together in Fig. 8c. Here we see that as with the annual cycle, the interannual variability of the baroclinic cycling term comes essentially from variability in the Ekman transport. Total interannual transports are plotted for the intergyre flux (red, as in Fig. 3a) and so is the Ekman transport with annual cycle removed (green). The latter is almost entirely furnished by baroclinic cycling. The total interannual baroclinic cycling term is shown (purple) for comparison. These curves show that much of the total interannual variability comes from Ekman transport via baroclinic cycling. In contrast with the annual cycle, for interannual time scales there is no longer a cancellation between Ekman and non-Ekman processes and for some features there is reinforcement, as for the (a) Total, eddy and meander terms

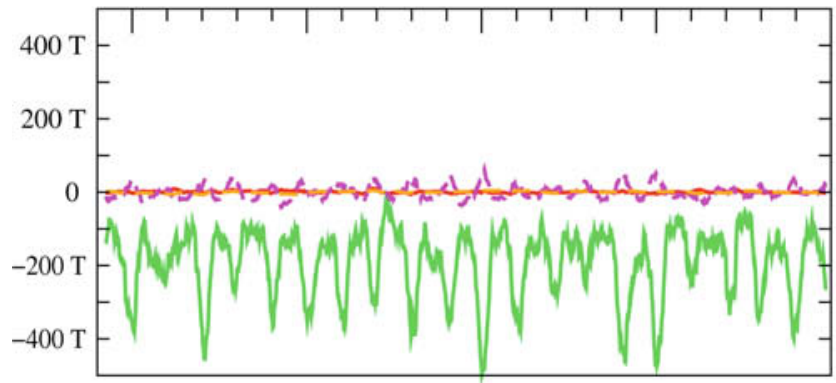

(b) Mean flow and cycling terms

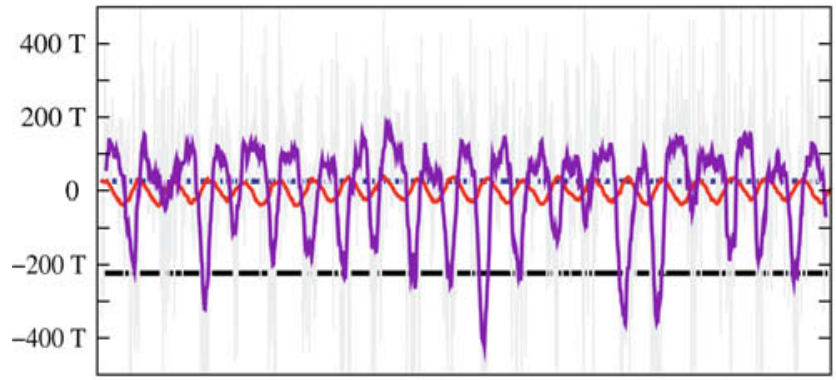

(c) Components of interannual variability

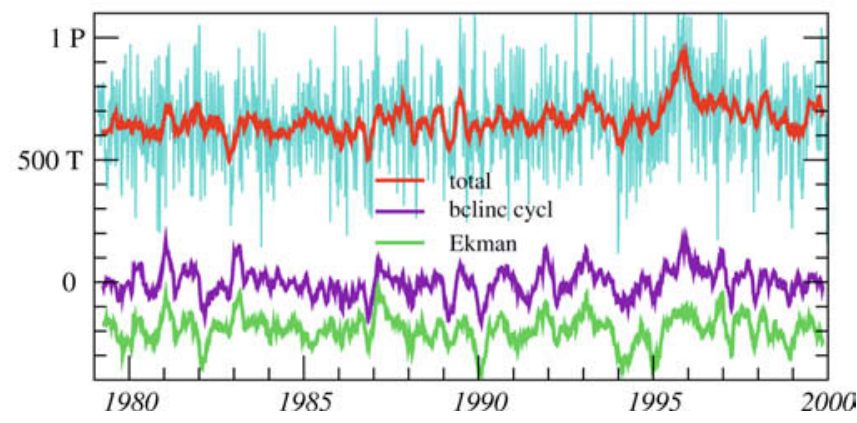

Fig. 8 As Fig. 6 but for the Ekman component of the intergyre heat transport. The unfiltered curve for the baroclinic cycling term $\left[v^{\prime}\right][T]$ is also shown (grey). c Components of the interannual variability (annual cycle removed and filtered with 105-day running mean). Total intergyre transport (red, unfiltered in turquoise), total Ekman contribution (green), baroclinic cycling term (also red) and Ekman contribution to baroclinic cycling term (purple)

1995/96 spike, which comes from a combination of baroclinic cycling and meander terms.

In summary, the Ekman transport provides the annual cycle of intergyre heat transport through the baroclinic cycling term $\left[v^{\prime}\right][\bar{T}]$, which depends on fluctuations in mean cross-stream velocity at upper levels. However, this annual cycle is almost perfectly opposed by spatial covariance between the normal velocity and the mean temperature along the stream. The Ekman transport also provides some of the interannual variability. The rest of the interannual variability comes from the Gulf-Stream meanders and transient eddies.

Is this residual variability also driven by the atmosphere in a more indirect way, or is it internally generated by ocean dynamics?

To begin to shed light on this question, a comparison will now be made with the annual cycle run, in which 
there is no interannual variability in the atmospheric forcing. Figure 9 shows the resulting intergyre heat transport and its decomposition (the years marked on the axis are merely nominal). Comparing Fig. 9 with Fig. 6 it can be seen that there is less interannual variability in the intergyre heat transport in the annual cycle run. The interannual standard deviation is $0.035 \mathrm{PW}$ for the (smoothed) annual cycle run compared to $0.063 \mathrm{PW}$ for the interannual run. However, the variability in the transient eddy and meander terms is just as strong in the annual cycle run. The difference lies chiefly in the Ekman-generated interannual variability which shows up in the baroclinic cycling term $\left[v^{\prime}\right][\bar{T}]$, and is of course largely absent from the annual cycle run (where there is no interannual signal from the wind stress). It seems, therefore, from a superficial examination that it is not necessary to appeal to atmospheric influences to explain the magnitude of the non-Ekman interannual variability. It can all be internally generated. Whether this is true for the individual features of the time series, or lower frequency components of the NAO signal, remains to be seen.

Further insight can be gained from an examination of spectra. Power spectra are shown in Fig. 10 for the total intergyre transport $[v T]$ and the transient eddy part $\left[v^{* *} T^{\prime *}\right.$. Results are compared for the interannual run (green) and the annual cycle run (blue). These spectra are calculated using the multi-taper method (Percival and Walden 1993) employed by Czaja and Marshall (2001), which gives smoother spectra, particularly at lower frequencies, which can be distinguished with greater confidence. In terms of total transport, the interannual run clearly has more power on interannual timescales than the annual cycle run, as expected due to the interannual variability in the forcing. On annual to seasonal time scales the two runs display a similar degree of variability, but as we approach the monthly and submonthly region region of the spectrum, the interannual run again shows more power. This is undoubtedly due to the lack of synoptic time scale wind forcing in the annual cycle run, which uses clmatological weekly mean wind stress and heat flux. The spectra for the transient eddy component of the intergyre transport is much closer for the two runs. There is a hint that there may be more interannual eddy variability in the interannual run but the signal is not significant. At shorter time scales the

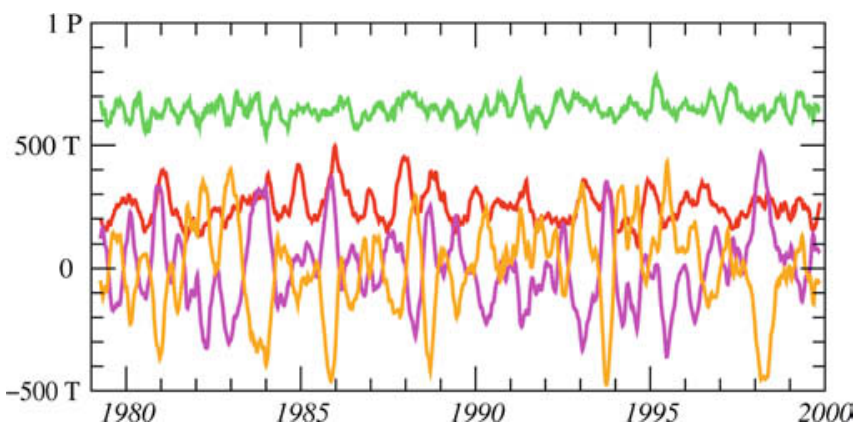

Fig. 9 As Fig. 6 abut for the annual cycle run (a) Total transport

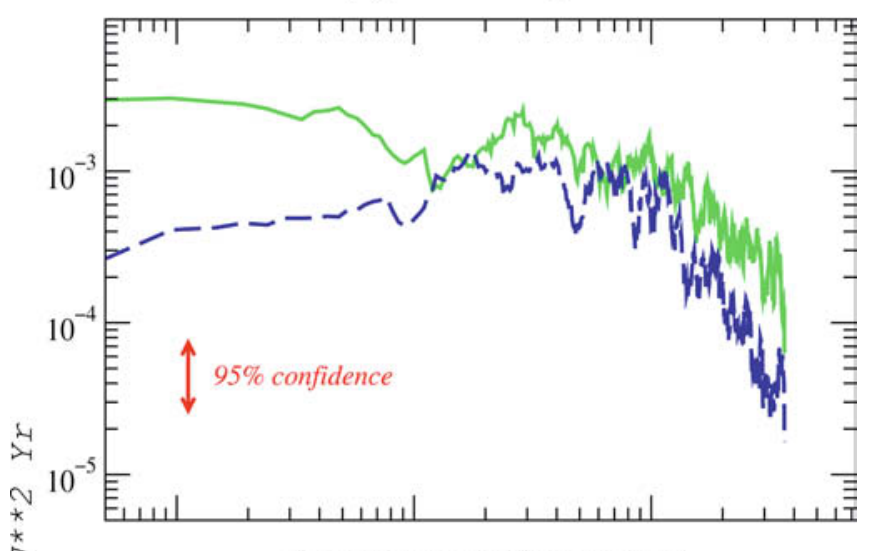

(b) Transient eddy transport

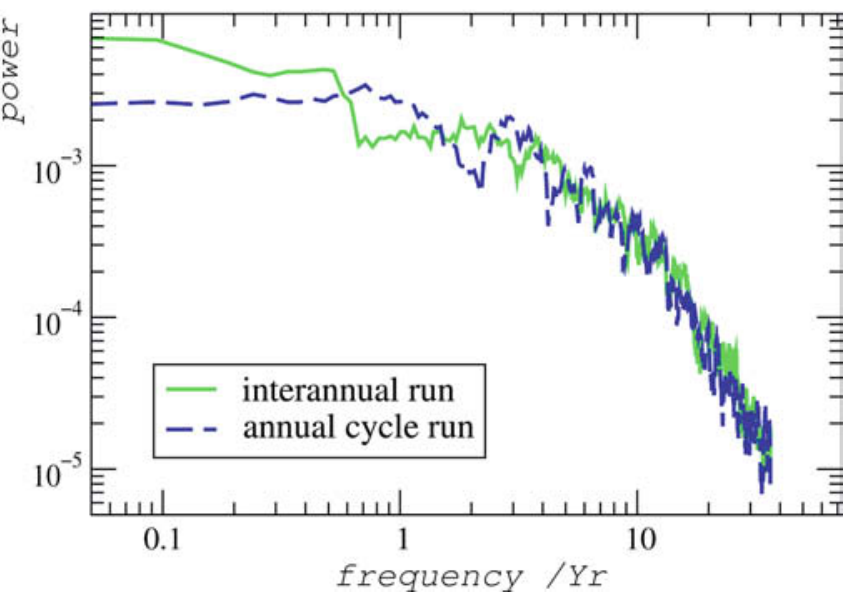

Fig. 10 Power spectra of the intergyre flux from the interannual run (green) and annual cycle run (blue). a total transport, b transport due to the transient eddy term $\left[v^{*} T^{*}\right]$

two spectra are very close, signalling that the coherent eddies are internally generated and that synoptic atmospheric forcing is irrelevant to their formation.

\section{Summary and discussion}

The aim of this work was to look at the effect of varying surface forcing on the ocean circulation in a realistic setting. We chose a simple index of the ocean circulation with relevance for climate studies: the intergyre heat transport across the Gulf Stream and North Atlantic current. This, and related indices were examined in terms of their annual cycle and interannual variability.

The annual cycle of the intergyre transport was found to be weak, even though separate components of the transport have a strong annual cycle. The mean overturning circulation along the Gulf Stream section, essentially driven by variations in the Ekman transport, has a large annual cycle and also contributes strongly to the interannual signal. The annual cycle provided by the vertical overturning circulation is effectively cancelled by the horizontal eddy-mean flow transport terms that characterise transient variations in the Gulf Stream and 
its associated front along the section. Transient eddies along the Gulf Stream also contribute to the interannual signal, and account for approximately half the mean intergyre transport. Analysis of an integration with a repeated smooth annual cycle forcing shows that the components of the interannual variability in the intergyre transport that are related to Gulf Stream eddies do not require interannual variability in the forcing for their generation or modulation. This does not mean that the eddy field and eddy transport is insensitive to external variations in forcing, but we do not find a strong intergyre signal on the time scales examined here. Nevertheless, area integrated measures of eddy variability diagnosed by Penduff et al.(2003) from the same model integration do show a tendency to follow the NAO signal with a 4-12 month lag, in accordance with TOPEX/Poseidon altimeter data. It appears therefore that the eddy heat transport is not strongly controlled by the general level of area integrated eddy activity. The heat transport carried by the Gulf Stream and subtropical gyre is yet more heavily influenced by the overturning component and has a strong annual cycle. This 'gyre' heat transport index is poorly related to the instantaneous strength of the Gulf Stream.

The imposed surface fluxes of heat and momentum affect the ocean model in very different ways. The response to wind forcing is rapid. Ekman transports are effectively set up immediately and are quite independent of the details of the model. Furthermore, the strong constraint on mass conservation imposed by the model's rigid lid upper boundary condition means that there is no ability to store heat by accumulating mass, and changes in the wind driven circulation immediately translate into changes in heat transport.

In contrast, the response to heat flux variations is subject to lag and storage. The heat capacity of the upper ocean is such that realistic anomalies in surface flux can build up temperature anomalies only slowly, and there is no requirement to redistribute heat. In fact the amount of seasonal and interannual storage of heat is so great that it dominates any attempt at a budget study for the 'implied' transport between gyres, making it difficult to attribute features of the diagnosed transport to individual surface heat flux variations. To illustrate this point, a surface budget study of the region between $15^{\circ} \mathrm{S}$ and the Gulf Stream section yields a peak to peak annual cycle of 5.6 PW in 'implied' intergyre transport with an interannual standard deviation of $0.285 \mathrm{PW}$. A similar exercise for the region between the Gulf Stream section and $70^{\circ} \mathrm{N}$ yields $3.4 \mathrm{PW}$ and $0.123 \mathrm{PW}$ respectively. These figures dwarf the directly calculated intergyre transport variability and yield time series' completely unrelated to it, demonstrating the dominance of strorage terms on all time scales considered. This result also offers some guidance as to what to expect from alternative forcing datasets. For example the NCEP reanalysis has some systematic differences in surface heat flux from that of the ECMWF (see Fig. 4 of Garnier et al. 2000) although the two products show greater consistency for the variability of the surface fluxes and for the wind stress. Differences in heat flux would in turn lead to a modified correction term in Eq. (1). We have seen how decoupled the influence of the surface flux is from the horizontal transport on these sub-decadal time scales. So just as it appears to be difficult to attribute interannual variations in the heat transport to features of the surface flux variability, it would also be difficult to predict how an alternative surface forcing would affect the transport variability. However, the breakdown of the transport into different dynamical components is a property of the ocean model and not of the details of the forcing, so conclusions based on this analysis are probably quite robust.

The NAO index discussed in the Introduction projects strongly onto the dominant modes of variability for both wind stress and heat flux forcing in the North Atlantic on all time scales. If the NAO index is defined as the monthly mean pressure difference between the Azores and Iceland normalised by its standard deviation and divested of its annual cycle, the simultaneous correlation coefficient with the intergyre heat transport is -0.39 . This figure drops to insignificant levels for all resolved leads and lags. The gyre transport is positively correlated at 0.37 . For annual mean data the correlations increase to -0.55 and 0.45 and for winter mean data (DJF) the figures are -0.36 and 0.69 respectively. So intergyre transports are negatively correlated with the NAO, essentially because increased westerlies imply increased southward Ekman transport at the latitude of the Gulf Stream section. Gyre transports, on the other hand, are positively correlated with the NAO, especially in winter. This must also be an Ekman effect as it is instantaneous and at the lower latitude of the subtropical gyre Ekman fluxes anomlies are directed northwards for positive NAO (see Visbeck et al. 2003). The strength of the wind driven gyre is better represented by the separated Gulf Stream transport (Fig. 5a) than the gyre transport (Fig. 3b) and we have already seen that the two are poorly related. The simultaneous correlation between the strength of the separated Gulf Stream and the NAO is extremely low at 0.02 (monthly mean), 0.05 (annual mean) and 0.07 (winter mean). A lag correlation analysis shows little evidence that these correlations improve when the NAO index leads, showing a noisy signature that reaches a value of 0.19 between 3 and 4 years. Even if variations in the wind do drive the variability of the gyre circulation, very little of the signal is subsequently transmitted to the gyre and intergyre heat transports. In summary, the effect of the NAO on these measures can be primarily explained as an almost simultaneous response to changes in wind stress.

\section{Conclusions}

Our prinicipal results can be summarised in the following seven points:

1. We have put forward an approach to diagnosing the major Atlantic Ocean heat transports by partitioning 
between 'intergyre' and 'gyre' components, which serves to isolate some aspects of the annual and interannual variability.

2. The ocean model transports $\sim 0.7 \mathrm{PW}$ northwards across the Gulf Stream - North Atlantic current. About half of this transport is effected by the transient eddies.

3. Because of a cancellation between the Ekman-overturning component and horizontal transient-mean flow ('meander') terms, the annual cycle in the intergyre heat transport is weak, much weaker than the annual cycle in gyre transport.

4. The Ekman component also accounts for a large fraction of the interannual variability in intergyre heat transport.

5. Terms associated with transient eddies also account for a significant fraction of the interannual variability, but appear to be independent of the surface forcing.

6. Perhaps surprisingly, the link between the wind-driven gyre circulation and the gyre and intergyre transport is poor, and the response of the former to interannual changes in wind stress is masked by internal variability.

7. It is difficult to attribute any aspect of transport variability to variations in surface heat flux on the time scales considered here because of the amount of storage in the system.

These conclusions serve to quantify some of our initial expectations from simple theories. There are further questions to be explored in terms of the response to surface forcing. It is hoped that longer integrations of this sort will become available so that these processes can be examined on longer time scales. With more realisations, more definitive quantifications can also be made for shorter time scales.

Acknowledgements We are very grateful to Arnaud Czaja for help with calculation of spectra and for useful comments. We thank the reviewer for comments that helped us to clarify some of the discussion. This work was funded by a fellowship from the European Union and the Centre National de la Recherche Scientifique. Support for computations was provided by the Institut du Développement et des Recources en Information Scientifique (IDRIS). The CLIPPER project was supported by the Institut Nationale des Sciences de l'Univers (INSU), the Institut Francais de Recherche pour l'Exploitation de la Mer (IFREMER), the Service Hydrographique et Océanographique de la Marine (SHOM) and the Centre Nationale d'Etudes Spatiales (CNES).

\section{References}

Barnier B (1998) Forcing the ocean. In: Chassignet E, Verron J (eds.) Ocean modelling and parametrization', Kluwer, Dardrecht, NL, pp 45-80

Bjerknes J (1964) Atlantic air-sea interaction. Adv Geophys 10: $1-82$

Crosnier L, B Barnier, Treguier A-M (2001) Aliasing of inertial oscillations in the $1 / 6^{\circ}$ Atlantic circulation Clipper model: impact on the mean meridional heat transport. Ocean Modelling 3: $21-32$
Czaja A, Marshall JC (2001) Observations of atmosphere-ocean coupling in the North Atlantic. QJR Meteorol Soc 127: 18931916

Eden C, Jung T (2001) North Atlantic interdecadal variability: oceanic response to the North Atlantic Oscillation (1865-1997). J Clim 14: 676-691

Frankignoul C, de Coetlogon G, Joyce TM, Dong S (2001) Gulf Stream variability and ocean-atmosphere interaction. J Phys Oceanogr 31: 3516-3529

Ganachaud A, Wunch C (2003) Large-scale ocean heat and freshwater transports during the world ocean circulation experiment. J Clim 16: 696-705

Garnier E, Barnier B, Siefridt L, Béranger K (2000) Investigating the 15 year air-sea flux climatology from the ECMWF reanalysis project as a surface boundary condition for ocean models. Int J Climatol 20: 1653-1673

Gulev S, Barnier B, Knochel H, Molines J.M, Cottet M(2003) Water mass transformation in the North Atlantic and its impact on the meridional circulation: insights from an ocean model forced by NCEP-NCAR reanalysis surface fluxes. J clim 16: 3085-3110

Hakkinen S (1999) Variability of the simulated meridional heat transport in the North Atlantic for periods 1951-1993. J Geophys Res 104: 10,991-11,007

Hansen DV, Bezdek HF (1996) On the nature of decadal anomalies in the North Atlantic sea surface termperature. J Geophys Res 101: 8749-8758

Hurrell JW (1996) Influence of variations in the extratropical wintertime teleconnections on Northern Hemisphere temperature. Geophys Res Lett 23: 665-668

Jayne SR, Marotzke J (2001) The dynamics of ocean heat transport variability. Rev Geophys 39: 386-411

Krahmann G, Visbeck M, Reverdin G (2001) Formation and propagation of temperature anomalies along the North Atlantic Current. J Phys Oceanogr 31: 1287-1303

Marshall JC, Johnson H, Goodman J (2001) A study of the interaction of the North Atlantic Oscillation with ocean circulation. J Clim 14: 1399-1421

Penduff T, Barnier B, Dewar WK, O’Brien JJ (2003) Dynamical response of the ocean eddy field to the North Atlantic Oscillation: a model-data comparison. J Phys Oceanogr (Accepted)

Pavia AM, Chassignet EP (2002) North Atlantic modelling of low frequency variability in mode water formation. J Phys Oceanogr 32: 2666-2680

Percival DB, Walden TA (1993) Spectral analysis for physical applications. Multitaper and conventional univariate techniques. Cambridge University Press, Cambridge, UK

Reynolds RW, Smith TM (1994) Improved global sea surface temperature analyses using optimum interpolation. J. Clim 7: 929-948

Saravanan R, McWilliams J (1997) Stochasticity and spatial response in interdecadal climate fluctuations. J Clim 10: 22992320

Sutton R, Allen M (1997) Decadal predictability of North Atlantic sea surface temperature and climate. Nature 388: 363-367

Taylor AH, Stephens JA (1998) The North Atlantic Oscillation and the latitude of the Gulf Stream. Tellus 50A: 134-142

Treguier A-M, Barnier B, de Miranda A, Molines J-M, Grima N, Imbard M, Madec G, C Messager Michel S (2001) An eddy permitting model of the Atlantic circulation: evaluating open boundary conditions. J Geophys Res 106: 22 ,11522,129

Visbeck M, Cullen H, Krahmann G, Naik N (1998) An ocean model's response to North Atlantic Oscillation like wind forcing. Geophys Res Lett 25: 4521-4524

Visbeck M, Chassignet EP, Curry RG, Delworth TL, Dickson RR, Krahmann G (2003) The ocean's response to North Atlantic Oscillation variability. In: The North Atlantic Oscillation: climate significance and environmental impacts, Hurrel JW, Kushnir Y, Ottersen G, Visbeck M,eds. Geophysical Monograph Series 134: pp 279 